\title{
Is Premenstrual Syndrome a Uterine Inflammatory Disease? Retrospective Evaluation of an Etiologic Approach
}

\author{
Jorge Lolas-Talhami1', Juana Lafaja-Mazuecos², Diego Ferrández-Sempere ${ }^{3}$ \\ ${ }^{1}$ Instituto de Investigaciones Ginecológicas, Santiago, Chile \\ Gynecology Department, NG Clínicas, Elche, Spain \\ ${ }^{3}$ Spine Surgery Department, NG Clínicas, Elche, Spain \\ Email: jlolast@yahoo.com, jlafaja@ng-clinicas.com, dferrandez@ng-clinicas.com
}

Received 21 April 2015; accepted 31 May 2015; published 3 June 2015

Copyright (C) 2015 by authors and Scientific Research Publishing Inc.

This work is licensed under the Creative Commons Attribution International License (CC BY).

http://creativecommons.org/licenses/by/4.0/

(c) (i)

\section{Abstract}

Objective: To retrospectively evaluate the efficacy of local uterine antibiotic and anti-inflammatory injections combined with cryotherapy for the treatment of severe Premenstrual Syndrome (PMS) and Premenstrual Dysphoric Disorder (PMDD). To validate the hypothesis of a uterine infectious/inflammatory etiology of PMS/PMDD. Methods: Clinical files of 161 women sequentially treated from September 1995 to April 2005, were collected for study. A subset of 148 patients (mean: $36.7 \pm 7.8$ years, range: 20.1 - 53.8 years) were eligible for statistical analysis. The ten most relevant PMS symptoms, namely depression, irritability, anxiety, fatigue, headache, edema, breast tenderness, abdominal bloating, pelvic pain and dysmenorrhea, were self-rated before and three menstrual cycles after treatment, using a 0 to 5 scale. The treatment consisted of cervical stromal antibiotic/anti-inflammatory injections combined with intracervical cryotherapy. Scores were compared using non-parametric tests for matched samples. Results: Before treatment, mean severity scores for the 10 symptoms were $3.97 \pm 1.17,4.26 \pm 0.88,3.41 \pm 1.23,3.91 \pm 0.94,3.35 \pm$ $1.71,2.28 \pm 1.69,2.13 \pm 1.63,4.51 \pm 0.63,2.28 \pm 1.30$, and $2.28 \pm 1.88$, respectively. Mean values after treatment were $0.54 \pm 0.91,0.51 \pm 0.91,0.32 \pm 0.70,0.42 \pm 0.74,0.43 \pm 0.96,0.22 \pm 0.53,0.39$ $\pm 0.73,1.01 \pm 0.94,0.28 \pm 0.69$, and $0.44 \pm 0.92$. All tests were statistically significant $(p<0.01)$. Conclusion: Both PMS physical and psycho-affective symptoms respond to local anti-inflammatory and antibiotic treatment of the uterus, showing a stable improvement after the treatment has ended. The results of this study suggest that the clinical pattern of PMS can be explained as an inflammatory mediated response to uterine infectious or traumatic insults. Further evidence is urgently needed in order to validate this innovative approach for widespread use in severe PMS/ PMDD cases.

\section{Keywords}

Premenstrual Syndrome, Premenstrual Dysphoric Disorder, Inflammatory Cytokines, 


\section{Cervix Injections, Cervix Cryotherapy}

\section{Introduction}

Premenstrual Syndrome (PMS) is a multi-symptomatic disorder characterized by the cyclic recurrence of symptoms during the luteal phase of the menstrual cycle. More than 200 behavioral, psychological and physical symptoms have been associated with PMS [1], but irritability, pelvic pain, migraine, breast tenderness, swelling and bloating are the ones most frequently observed [2]. Up to 85 percent of menstruating women report having one or more premenstrual symptoms, and 2 to 10 percent report disabling symptoms severe enough to warrant treatment, usually consisting of ovulation suppressors, painkillers, anti-inflammatory drugs, psychoactive drugs, and several other symptomatic medications [3]. Premenstrual Dysphoric Disorder (PMDD) is a severe psychoaffective variant of PMS with a prevalence of $3 \%$ to $8 \%$ of fertile women [4]. The cyclic nature of PMDD and the limited knowledge of this condition, make it easy to misdiagnose as a bipolar disorder [5] [6].

Different factors have been associated with the onset of PMS, such as trauma from delivery, sexual activity, stress, genital surgery, and invasive tests; however, its pathophysiology remains unknown and may be complex and multifactorial [7]. The role of ovarian hormones is unclear given that circulating sex hormone levels are typically normal in women with PMS. Changes in hormone levels may influence neurotransmitters such as serotonin; and an enhanced sensitivity to progesterone combined with underlying serotonin deficiency could play a role as well [1]. Other authors suggest that an infectious/inflammatory condition of the ovaries, uterus or other organs could be the origin of this clinical picture [8], as cell-mediated immunity decays after ovulation to protect the implanting embryo [1]. A recent study correlates the severity of some PMS symptoms with the levels of certain inflammatory mediators [9].

\section{Objective}

The main objective of this study is to retrospectively evaluate the efficacy of local uterine antibiotic and antiinflammatory injections combined with cryotherapy for the treatment of women diagnosed with longstanding severe premenstrual syndrome, non-responsive or intolerant to symptomatic and hormonal drugs.

A secondary objective is to validate the hypothesis of a uterine infectious/inflammatory etiology of PMS and PMDD.

\section{Methods}

Over 1600 women have been treated of severe PMS by a single gynecologist (JLT) with an exclusive focus on this condition since 1971, using local cervical antibiotic and anti-inflammatory therapy. All medical interviews and colposcopic examinations were videotaped after expressed consent since 1982. The most relevant ten PMS symptoms (depression, irritability, anxiety, fatigue, headache, edema, breast tenderness, abdominal bloating, pelvic pain and dysmenorrhea) were self-rated by patients using a 0 to 5 discrete scale. The average time (in days) of severe symptoms before and after treatment was registered.

Clinical files of 161 women sequentially treated from September 1995 to April 2005, were collected for study. The scores of the main PMS symptoms before and 3 cycles after completing treatment, were considered for evaluation. Longer follow-up was not consistently recorded to be included in the study.

According to the inclusion criteria (Table 1), 148 women (mean age $36.7 \pm 7.8$ years, range 20.1 - 53.8 years) were eligible for statistical analysis.

\subsection{Procedure}

All actions in this study were carried out in accordance with the code of ethics of the Declaration of Helsinki. Informed consent was either signed by the patient or video-recorded after a detailed explanation about the procedure was given.

The initial treatment included 4 to 8 cervical injections on a weekly basis, bypassing the menstrual periods. A needle was placed 15 to $20 \mathrm{~mm}$ deep into the cervical stroma. Gentamicin $80 \mathrm{mg}+1 \mathrm{ml}$ lidocaine $2 \%$ were injected, followed by diclofenac $75 \mathrm{mg}$ immediately thereafter. 
The second phase consisted of a 3 step endocervical cryotherapy with freezing periods of 5 to 20 min and 15 min defrosting intervals.

The final phase included 3 to 5 further injections until a sensible and stable symptomatic improvement was reached, otherwise a second cryotherapy was practiced.

Antibiotic prophylaxis was prescribed after cryotherapy with oral metronidazole 500 mg every $12 \mathrm{~h}$ for 5 days plus antiseptic vaginal tablets. Permeability of the cervical canal was checked after 2 weeks and dilatation maneuvers were performed when necessary.

\subsection{Statistical Analysis}

Normality was studied using Kolmogorov-Smirnov test. Pre and post-treatment symptom scores and time span were compared using Wilcoxon signed rank sum test. Pre and post-treatment proportion of patients scoring 3, 4 or 5 were compared using McNemar test. Significance was established at $\mathrm{p}<0.01$.

\section{Results}

\subsection{Data Processing}

The distribution of severity scores for every main symptom of PMS, before and after treatment, is depicted in Figure 1. Table 2 and Table 3 show mean severity scores and rates for highest severity scores (3, 4 and 5) before and after treatment respectively.

Mean duration of severe symptoms before treatment was $12.89 \pm 4.34$ days, which dropped to $2.59 \pm 2.04$ days after treatment $(\mathrm{p}<0.01)$.

Thirty two patients needed a second cryotherapy procedure (21.61\%).

\section{Table 1. Inclusion criteria.}

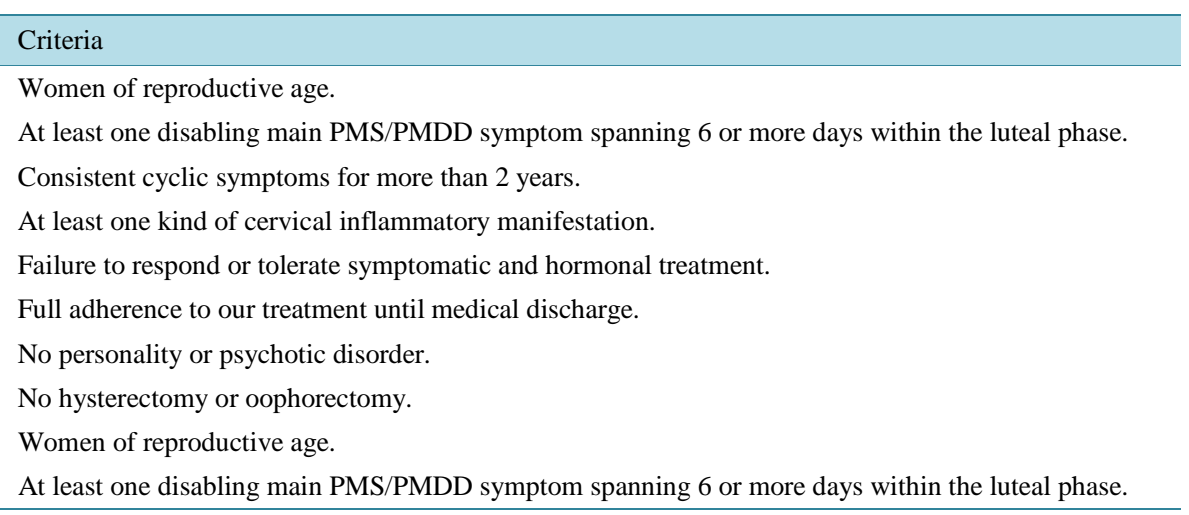

Table 2. Mean severity scores for the 10 most relevant PMS symptoms in a 0 to 5 scale $\left(^{*} \mathrm{p}<\right.$ 0.01).

\begin{tabular}{cccc}
\hline Symptom & Score before treatment & Score after treatment & Relative improvement \\
\hline Depression & $3.97 \pm 1.17$ & $0.54 \pm 0.91^{*}$ & $86.4 \%$ \\
Irritability & $4.26 \pm 0.88$ & $0.51 \pm 0.91^{*}$ & $87.9 \%$ \\
Anxiety & $3.41 \pm 1.23$ & $0.32 \pm 0.70^{*}$ & $90.7 \%$ \\
Fatigue & $3.91 \pm 0.94$ & $0.42 \pm 0.74^{*}$ & $89.3 \%$ \\
Headache & $3.35 \pm 1.71$ & $0.43 \pm 0.96^{*}$ & $87.1 \%$ \\
Edema & $2.28 \pm 1.69$ & $0.22 \pm 0.53^{*}$ & $90.2 \%$ \\
Breast tenderness & $2.13 \pm 1.63$ & $0.39 \pm 0.73^{*}$ & $81.6 \%$ \\
Abdominal bloating & $4.51 \pm 0.63$ & $1.01 \pm 0.94^{*}$ & $77.5 \%$ \\
Pelvic pain & $2.28 \pm 1.30$ & $0.28 \pm 0.69^{*}$ & $87.5 \%$ \\
Dysmenorrhea & $2.28 \pm 1.88$ & $0.44 \pm 0.92^{*}$ & $80.8 \%$ \\
\hline
\end{tabular}


Table 3. Rate of highest severity scores (3, 4 and 5) for the 10 most relevant PMS symptoms ( $\left.{ }^{*} \mathrm{p}<0.01\right)$.

\begin{tabular}{ccc}
\hline Symptom & Rate before treatment & Rate after treatment \\
\hline Depression & $87.84 \%$ & $5.41 \%{ }^{*}$ \\
Irritability & $94.59 \%$ & $5.41 \%^{*}$ \\
Anxiety & $84.46 \%$ & $2.03 \%^{*}$ \\
Fatigue & $95.95 \%$ & $2.03 \%^{*}$ \\
Headache & $78.38 \%$ & $4.73 \%^{*}$ \\
Edema & $49.32 \%$ & $0.68 \%{ }^{*}$ \\
Breast tenderness & $47.30 \%$ & $2.03 \%{ }^{*}$ \\
Abdominal bloating & $99.32 \%$ & $8.78 \%{ }^{*}$ \\
Pelvic pain & $47.97 \%$ & $2.70{ }^{*}$ \\
Dysmenorrhea & $50.68 \%$ & $4.73 \%{ }^{*}$ \\
\hline
\end{tabular}
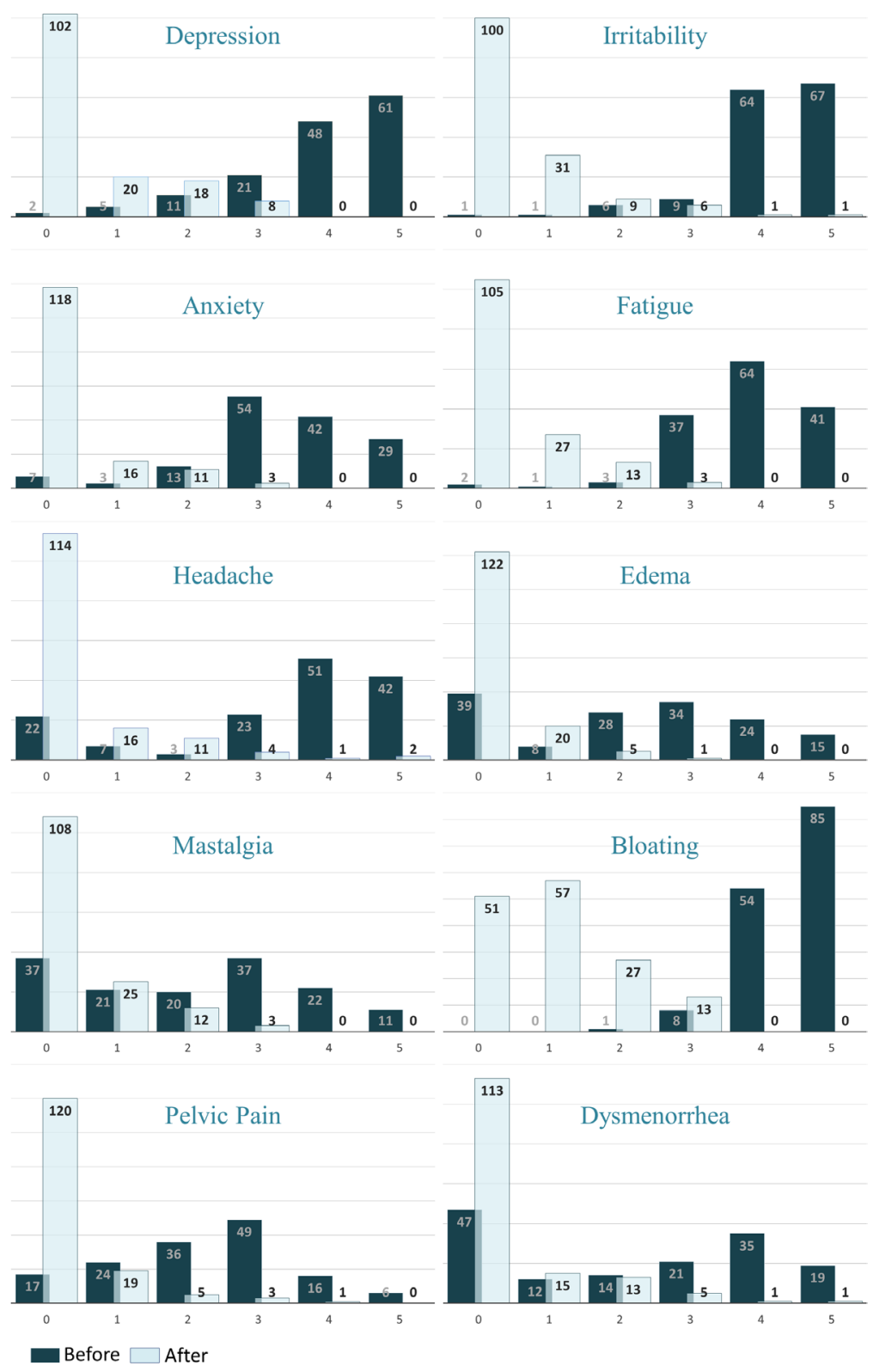

Figure 1. Severity score histograms before and after treatment. 


\subsection{Clinical Observations}

Regarding the use of endocervical cryotherapy, the most commonly observed reaction consisted of blushing, discomfort or even sadness, during defrosting intervals. An abundant, sometimes rusty, mucous discharge appeared consistently within the first defrosting interval, and mildly after subsequent steps. In actively symptomatic patients (most of them remain oligosymptomatic after injections), peaceful and deep well-being feelings have been described during freezing periods, which revert with defrosting. This phenomenon has been named by the authors control rods effect, by analogy with the control mechanism in a nuclear reactor.

In addition to side effects commonly associated with the use of parenteral drugs and cryotherapy, a transient worsening of premenstrual symptoms has been observed after cryotherapy, which span for some days and improve with oral anti-inflammatory treatment.

\section{Discussion}

PMS/PMDD can be a severely disabling disorder, which may lead patients to time off work, social isolation and even suicide in extreme cases [7]-[10]. In our experience, symptoms occur mainly during the luteal half of the cycle, although after long chronicity, some manifestations are present all along the cycle. In such cases, it is very difficult to correctly diagnose this condition, and a variety of diagnoses have been found in our series and others [11], namely, depressive disorder, fibromyalgia, chronic fatigue syndrome or psycho-somatic disorder; nevertheless, cyclicity is not ever completely lost for all symptoms. For this reason, pre-existent depressive disorder, fibromyalgia or other diseases have not been considered exclusion criteria in our series, unlike in other publications. Another remarkable difference in terms of inclusion criteria was the requirement of only one disabling cyclic symptom to set a diagnosis of severe PMS. In our opinion, other published scoring methods reflect the degree of polymorphism rather than a subjective perception of severity.

Although treating benign cervical lesions, including chronic cervicitis, ectropion, polips, cysts, etc., has been broadly considered unnecessary, different treatment modalities have been proposed when locally symptomatic [12] [13]. A series of women presenting with non-specific inflammatory changes, were treated in the early 80's by senior author (JLT) when he was Chairman of the Colposcopy Unit at Hospital Militar de Santiago, Chile. Local or systemic antibiotic and anti-inflammatory drugs as well as electro-cautery were used, irrespective of the presence of symptoms. Unexpectedly, these patients reported premenstrual symptoms improvement, either physical or psychological. Those empirical observations led him to further experiment with different approaches based on antibiotic and anti-inflammatory combinations, ultrasounds, electro-cautery and cryotherapy, until the aforementioned protocol was standardized.

With this experience and positive results it was possible to hypothesize that PMS could be an infectiousinflammatory disease and all of its symptoms might be caused by inflammatory cytokines, acting on distant targets. Different studies claim this mechanism for migraine and psycho-affective disturbances, which in turn are common symptoms of PMS. The role of prostaglandin E2 is clearly established in migraine [14]. Cyclo-oxygenase inhibitors have proved to be active against major depression [15]. Markers like C reactive protein, TNF- $\alpha$ and IL-6 have been associated to mental disorders [16]-[19]. Clinical association between mood changes and dysmenorrhea has also been reported [20]. Some authors even claim a role for infection in behavioral abnormalities [21]-[24].

Bertone-Johnson has recently published the first study to correlate PMS symptoms with levels of inflammatory cytokines. Emotional state score was linearly correlated to IL-2 level while physical/behavioral score was linearly correlated to IL-4 and IL-12 levels in PMS patients. Additionally, levels of IL-4, IL-10, IL-12 and IFN- $\gamma$ were significantly higher in PMS patients compared to control patients [9].

Acne and genital pruritus are common manifestations during the luteal phase in PMS patients. Luteal progesterone inhibits type 1 helper T cells by stimulating secretion of IL- 4 and IL-10 from type 2 helper T cells. That leads to less effective control of fungi, viruses, and intracellular bacteria such as Propionibacterium acnes, Chlamydia trachomatis, Helicobacter pylori or Candida albicans [1], which could explain either acne or pruritus.

Some symptoms like dry skin, anhidrosis during exercise or hair loss, have been found to incidentally improve after treatment in our series. Normal function of cutaneous annexes could be disrupted by inflammatory mediators; in fact, prostaglandins are known to be involved [25] [26].

Our observations together with a growing literature supporting a new infectious-inflammatory-immune para- 
digm in the etiology of previously misunderstood diseases, should change the approach to PMS as a hormonal or psychosomatic disorder which had been followed until now. A toxic environment attributable to circulating inflammatory cytokines is somehow responsible for a so varicolored clinical picture, which we now call inflammatory cyclic hysterotoxemia. The uterine cervix seems to behave as an active cytokine-delivering tissue into the bloodstream, which would explain the control rods effect when frozen.

Early experience with stromal injections alone showed high incidence of recurrence of PMS symptoms after weeks or months. The added intracervical cryotherapy to the treatment resulted in better response and stability, and prevented recurrence through an unknown mechanism which could be attributed to a direct bacteriolytic effect. Additionally, it is possible that the profuse mucous discharge from intracervical glands during defrosting periods could help to eliminate a relevant bacterial reservoir, responsible for reinfections. The fact that oral doxycycline provides long lasting improvement of PMS symptoms compared to placebo, supports the infectious hypothesis as well [8]. Thus, PMS patients cured from infection and chronic inflammation of the uterus, should be considered free of PMS, so long as they don't get again infected-inflamed.

The fact of an infectious etiology of PMS must be considered in future research. Millions of women might benefit from this technique or even less invasive therapies. Hormonal treatment can help, but it is not free of side effects and, following the lines of our work, it is not addressing the source of the problem. We consider that the treatment proposed in this work goes to the source of the varied symptomatology found in the PMS and helps to explain the failures shown with the different treatments presently in place.

Placebo effect in PMS treatments has been rated as high as $25 \%$ - 50\% [27]. However, only symptomatic treatments have been compared to placebo so far. The retrospective nature of this study prevented the possibility of a placebo control group. In any case, the option of offering a placebo could be seen as ethically controversial, given that all these patients, most of them in despair, have followed multiple therapies with no effect for at least 2 years and that this technique is complex and highly time consuming. Furthermore, the high level of significance in our series makes placebo effect less likely to be assumed for the majority of cases treated.

We are aware of the limitations of this study in terms of follow up and level of evidence, but its technical aspect will definitely help other researchers to further advance these promising approach in future prospective studies.

Finally, one relevant observation to highlight is the careful study of the uterine cervix in order to establish an altered condition of this organ. Many cases are overlooked due to different estimations of what constitutes abnormality and a lack of full physical and lab examination.

\section{Conclusions}

Both PMS physical and psycho-affective symptoms respond to local anti-inflammatory and antibiotic treatment of the uterus as we have described and show a stable improvement after the treatment has ended.

The results of this study suggest that the whole clinical picture of PMS or PMDD can be explained as an inflammatory mediated response to uterine infectious or traumatic insults, cyclically modulated by hormonalimmune variations.

Further evidence is urgently needed in order to validate this innovative approach with high therapeutic potential, for widespread use in severe PMS/PMDD cases.

\section{Acknowledgements}

We would like to thank Mrs. Ángela de la Serna Fernández for her thorough revision of video-recordings and tireless work in aid of all PMS patients, through her blog hysterotoxemia.com.

\section{Funding Sources and Conflicts of Interest}

The authors declare that they are the only source of funding for this paper and they solely are responsible for the study design, data collection, statistical analysis, interpretation of results, writing of this report and decision to publish. Therefore, no conflicts of interest exist in any regard.

\section{References}

[1] Doyle, C., Ewald, H.A.S. and Ewald, P.W. (2007) Premenstrual Syndrome: An Evolutionary Perspective on Its Causes 
and Treatment. Perspectives in Biology and Medicine, 50, 181-202. http://dx.doi.org/10.1353/pbm.2007.0015

[2] Lolas, J. (1995) Síndrome Premenstrual desde una Nueva Perspectiva. Santiago de Chile, Texido, 1-199.

[3] Lete, I., Dueñas, J.L., Serrano, I., Doval, J.L., Martínez-Salmeán, J., Coll, C., Pérez-Campos, E. and Arbat, A. (2011) Attitudes of Spanish Women toward Premenstrual Symptoms, Premenstrual Syndrome and Premenstrual Dysphoric Disorder: Results of a Nationwide Survey. European Journal of Obstetrics Gynecology Reproductive Biology, 159, 115-118. http://dx.doi.org/10.1016/j.ejogrb.2011.06.041

[4] Rapkin, A.J. and Lewis, E.I. (2013) Treatment of Premenstrual Dysphoric Disorder. Women's Health (London, England), 9, 537-556. http://dx.doi.org/10.2217/whe.13.62

[5] Studd, J. (2012) Severe Premenstrual Syndrome and Bipolar Disorder: A Tragic Confusion. Menopause International, 18, 82-86. http://dx.doi.org/10.1258/mi.2012.012018

[6] Teatero, M.L., Mazmanian, D. and Sharma, V. (2014) Effects of the Menstrual Cycle on Bipolar Disorder. Bipolar Disorders, 16, 22-36. http://dx.doi.org/10.1111/bdi.12138

[7] Lolas, J. (1993) Síndrome Premenstrual: Un Ignorado Problema de Salud Pública. Revista Médica de Chile, 121, 560566.

http://ng-clinicas.com/wp-content/uploads/2015/04/Lolas-J.-Premenstrual-syndrome-a-neglected-public-health-proble $\underline{\text { m.pdf }}$

[8] Toth, A., Lesser, M.L., Naus, G., Brooks, C. and Adams, D. (1988) Effect of Doxycycline on Pre-Menstrual Syndrome: A Double-Blind Randomized Clinical Trial. Journal of International Medical Research, 16, 270-279. http://www.ncbi.nlm.nih.gov/pubmed/3049185

[9] Bertone-Johnson, E.R., Ronnenberg, A.G., Houghton, S.C., Nobles, C., Zagarins, S.E., Takashima-Uebelhoer, B.B., Faraj, J.L. and Whitcomb, B.W. (2014) Association of Inflammation Markers with Menstrual Symptom Severity and Premenstrual Syndrome in Young Women. Human Reproduction, 29, 1987-1994. http://dx.doi.org/10.1093/humrep/deu170

[10] Heinemann, L.A.J., Minh, T.D., Filonenko, A. and Uhl-Hochgräber, K. (2010) Explorative Evaluation of the Impact of Severe Premenstrual Disorders on Work Absenteeism and Productivity. Women's Health Issues, 20, 58-65. http://www.ncbi.nlm.nih.gov/pubmed/20123176 http://dx.doi.org/10.1016/j.whi.2009.09.005

[11] Halbreich, U. (2004) The Diagnosis of Premenstrual Syndromes and Premenstrual Dysphoric Disorder-Clinical Procedures and Research Perspectives. Gynecological Endocrinology, 19, 320-334. http://dx.doi.org/10.1080/0951590400018215

[12] Darwish, A.M.M. and Zahran, K.M. (2013) Trichloroacetic Acid Application versus Spray Monopolar Diathermy for Treating Benign Cervical Lesions: A Randomized Controlled Clinical Trial. Journal of Lower Genital Tract Disease, 17, 248-254. http://dx.doi.org/10.1097/LGT.0b013e31827527e3

[13] Yang, K., Li, J., Liu, Y., Ma, B., Roberts, H., Tan, J., Tian, J., Wu, T. and Zhang, P. (2007) Microwave Therapy for Cervical Ectropion. Cochrane Database of Systematic Reviews, 4, CD006227. http://www.ncbi.nlm.nih.gov/pubmed/17943899

[14] Antonova, M. (2013) Prostaglandins and Prostaglandin Receptor Antagonism in Migraine. Danish Medical Journal, 60, B4635. http://dx.doi.org/10.1186/1129-2377-1-s1-p114

[15] Müller, N., Schwarz, M.J., Dehning, S., Douhe, A., Cerovecki, A., Goldstein-Müller, B., Spellmann, I., Hetzel, G., Maino, K., Kleindienst, N., Möller, H.-J., Arolt, V. and Riedel, M. (2006) The Cyclooxygenase-2 Inhibitor Celecoxib has Therapeutic Effects in Major Depression: Results of a Double-Blind, Randomized, Placebo Controlled, Add-On Pilot Study to Reboxetine. Molecular Psychiatry, 11, 680-684. http://www.nature.com/mp/journal/v11/n7/full/4001805a.html http://dx.doi.org/10.1038/sj.mp.4001805

[16] Baumeister, D., Russell, A., Pariante, C.M. and Mondelli, V. (2014) Inflammatory Biomarker Profiles of Mental Disorders and Their Relation to Clinical, Social and Lifestyle Factors. Social Psychiatry and Psychiatric Epidemiology, 49, 841-849. http://dx.doi.org/10.1007/s00127-014-0887-z

[17] Khandaker, G.M., Pearson, R.M., Zammit, S., Lewis, G. and Jones, P.B. (2014) Association of Serum Interleukin 6 and C-Reactive Protein in Childhood with Depression and Psychosis in young Adult Life: A Population-Based Longitudinal Study. JAMA Psychiatry, 71, 1121-1128. http://dx.doi.org/10.1001/jamapsychiatry.2014.1332

[18] Shang, Y.-X., Ding, W.-Q., Qiu, H.-Y., Zhu, F.-P., Yan, S.-Z. and Wang, X.-L. (2014) Association of Depression with Inflammation in Hospitalized Patients of Myocardial Infarction. Pakistan Journal of Medical Sciences, 30, $692-697$. http://dx.doi.org/10.12669/pjms.304.4584

[19] Brietzke, E., Stertz, L., Fernandes, B.S., Kauer-Sant’anna, M., Mascarenhas, M., Escosteguy Vargas, A., Chies, J.A. and Kapczinski, F. (2009) Comparison of Cytokine Levels in Depressed, Manic and Euthymic Patients with Bipolar 
Disorder. Journal of Affective Disorders, 116, 214-217. http://dx.doi.org/10.1016/j.jad.2008.12.001

[20] Balık, G., Ustüner, I., Kağıtc1, M. and Sahin, F.K. (2014) Is There a Relationship between Mood Disorders and Dysmenorrhea? Journal of Pediatric and Adolescent Gynecology, 27, 371-374. http://dx.doi.org/10.1016/j.jpag.2014.01.108

[21] Simanek, A.M., Cheng, C., Yolken, R., Uddin, M., Galea, S. and Aiello, A.E. (2014) Herpesviruses, Inflammatory Markers and Incident Depression in a Longitudinal Study of Detroit Residents. Psychoneuroendocrinology, 50, 139148. http://dx.doi.org/10.1016/j.psyneuen.2014.08.002

[22] Harrison, N.A., Brydon, L., Walker, C., Gray, M.A., Steptoe, A., Dolan, R.J. and Critchley, H.D. (2009) Neural Origins of Human Sickness in Interoceptive Responses to Inflammation. Biological Psychiatry, 66, 415-422. http://www.biologicalpsychiatryjournal.com/article/S0006-3223(09)00323-0/fulltext http://dx.doi.org/10.1016/j.biopsych.2009.03.007

[23] Canli, T. (2014) Reconceptualizing Major Depressive Disorder as an Infectious Disease. Biology of Mood \& Anxiety Disorders, 4, 10. http://www.biolmoodanxietydisord.com/content/4/1/10 http://dx.doi.org/10.1186/2045-5380-4-10

[24] Canli, T. (2014) Is Depression an Infectious Disease? TEDxSBU, USA. https://www.youtube.com/watch?v=1dD29XHp6CU\&feature=youtu.be

[25] Zouboulis, C.C. (2005) Sebaceous Glands and the Prostaglandin Pathway-Key Stones of an Exciting Mosaic. Journal of Investigative Dermatology, 125, x-xi. http://dx.doi.org/10.1111/j.0022-202X.2005.23922.x

[26] Garza, L.A., Liu, Y., Yang, Z., Alagesan, B., Lawson, J.A., Norberg, S.M., Loy, D.E., Zhao, T., Blatt, H.B., Stanton, D.C., Carrasco, L., Ahluwalia, G., Fischer, S.M., FitzGerald, G.A. and Cotsarelis, G. (2012) Prostaglandin $D_{2}$ Inhibits Hair Growth and Is Elevated in Bald Scalp of Men with Androgenetic Alopecia. Science Translational Medicine, 4, 126ra34. http://dx.doi.org/10.1126/scitranslmed.3003122

[27] Dickerson, L.M., Mazyck, P.J. and Hunter, M.H. (2003) Premenstrual Syndrome. American Family Physician, 67, 1743-1752. http://www.ncbi.nlm.nih.gov/pubmed/12725453 